\title{
Cenelestao
}

\section{Framework conceitual para o desenvolvimento de Curadoria Digital para pessoas com baixa visão}

\author{
Kettuly Costa Machado \\ Mestra; Pontifícia Universidade Católica do Paraná, Curitiba, PR, Brasil; \\ kettulykeps@ hotmail.com \\ Willian Barbosa Vianna \\ Doutor Universidade Federal de Santa Catarina, Florianópolis, SC, Brasil; \\ wpwilliam@hotmail.com \\ Ana Clara Cândido \\ Doutora; Universidade Federal de Santa Catarina, Florianópolis, SC, Brasil; \\ acc.anaclara@gmail.com
}

\begin{abstract}
Resumo: O objetivo deste estudo foi propor um framework conceitual para o desenvolvimento de Curadoria Digital para pessoas com baixa visão. Os procedimentos metodológicos abrangem duas etapas principais: a aplicação da ferramenta Proknow-C, para a análise do portfólio bibliográfico, e a consulta a um grupo de especialistas, no âmbito teórico e prático, sobre o tema de Curadoria Digital. A partir da convergência da literatura e da percepção dos especialistas consultados, foram identificados os objetos digitais que compõem o contexto informacional. $\mathrm{O}$ embasamento teórico possibilitou o desenvolvimento da proposta de um framework conceitual e do exercício de aplicação com a finalidade de demonstrar o seu funcionamento. Por fim, o framework conceitual desenvolvido pode contribuir como suporte aos profissionais que trabalham com a informação digital nos processos de tratamento de um objeto digital e, consequentemente, auxilia os profissionais da gestão da informação.
\end{abstract}

Palavras-chave: Gestão da informação. Framework conceitual. Curadoria digital. Objeto digital. Pessoas com baixa visão.

\section{Introdução}

Os diversos desenvolvimentos tecnológicos têm possibilitado a vivência propagada no universo digital ao longo dos anos. Nestes termos, a informação digital tem crescido e superado os formatos tradicionais. Tal expansão se dá, sobretudo, ao grande número de dados sendo criados diariamente pelas pessoas e pelas máquinas. 
Estima-se que $0,5 \%$ dos dados do mundo passam por alguma análise. A propagação de variados dispositivos, tais como os smartphones e os computadores, proporciona o aumento do acesso à internet e, assim, origina a replicação dos dados e da informação nos últimos anos, o que aumenta a cada dois anos e pode chegar a um aumento de 40 ZB em 2020 (BATIMARCHI, 2012). Diante desse cenário, a Curadoria Digital apresenta-se como proposta relevante, ao englobar todas as ações necessárias para manter os objetos e os dados digitalizados e os nascidos digitais, ao longo de todo o seu ciclo de vida garantindo a disponibilidade para as gerações atuais e futuras (YAKEL, 2007).

A Curadoria Digital engloba não só os processos de arquivamento digital e preservação digital, bem como todos os processos necessários para uma boa criação e gestão de dados. Além da capacidade de agregar valor aos dados, a fim de gerar novas fontes de informação e conhecimento. Tendo em consideração a relevância e as potencialidades da Curadoria Digital na área da Ciência da Informação, com aplicações em diversos campos do conhecimento para o atendimento de problemas reais, esse estudo tem como pergunta desta pesquisa: como identificar, organizar e gerenciar conteúdos digitais para pessoas com baixa visão?

Sendo assim, o objetivo geral do estudo é desenvolver um framework conceitual para o gerenciamento da informação de uma curadoria digital para pessoas com baixa visão. Referente ao objeto de análise do estudo, o número de pessoas com deficiência no mundo e no Brasil tem aumentado (INSTITUTO BRASILEIRO DE GEOGRAFIA E ESTATÍSTICA, 2011). No Brasil, o total dessas pessoas representam $24 \%$ da população, o que fez com que o país desenvolvesse algumas políticas de inclusão. A deficiência para Amaral (2003) é toda alteração do corpo ou aparência física de um órgão ou de uma função, qualquer que seja sua causa, tendo como características perdas ou alterações que podem ser temporárias ou permanentes.

As deficiências têm subdivisões e especificidades, e para este trabalho, o foco foi na inclusão digital para pessoas com deficiência visual, em particular, a pessoa com baixa visão. As pessoas com deficiência visual têm a maior estatística em relação aos outros tipos de deficiências, $18,8 \%$ da população, que 
se subdivide em cegueira e baixa visão. É importante mencionar a existência de um sistema Braille bem definido e em funcionamento para as pessoas com cegueira, fato que proporciona a inclusão. No caso das pessoas com baixa visão, essa inclusão pode dar margem para alguns questionamentos e dúvidas. Para fins de enquadramento, neste estudo, considera-se pessoa com baixa visão aquela que tem alteração da capacidade funcional da visão, decorrente de inúmeros fatores isolados ou associados, tais como: baixa acuidade visual significativa, redução importante do campo visual, alterações corticais e/ou de sensibilidade aos contrastes, que interferem ou que limitam o desempenho visual do indivíduo (BRASIL, 2006).

Para Paschoal (1993) a baixa visão é definida como a perda severa da visão que não pode ser corrigida por tratamento clínico ou cirúrgico nem por óculos convencionais. Ainda, ela está relacionada com a capacidade visual que uma pessoa possuir situada entre 20/40 e 20/200, após correção. Na atual sociedade, com todos os avançados tecnológicos, as pessoas com deficiência, por vezes, podem se sentir excluídas e privadas desses desenvolvimentos. E ainda, tendem a serem excluídas do contato e acesso ao meio digital, ocasionando limites e barreiras no acesso à informação digital. Não é perceptível como estão sendo integrados ou organizados os conteúdos digitais para pessoas com baixa visão. Logo, há uma abertura para o estudo e gerenciamento desse tipo de conteúdo, na qual se pode questionar a forma como estas pessoas têm acesso à informação digital. A necessidade de cuidado e tratamento da informação digital converge com a proposta deste estudo. O suporte estabelecido no âmbito da Curadoria Digital demonstra a relevância da gestão da informação. Sendo esta uma área que estuda e aplica conceitos e práticas para o uso correto da informação em qualquer formato (SOLIMAN, 2000). 


\section{Curadoria Digital}

Entre os estudos que abordam a informação digital e as suas ramificações, como a Curadoria Digital enquanto prática utilizada no gerenciamento de documentos digitais, destacam-se:

Sayão e Sales (2012), ao tratarem da Curadoria Digital e da preservação de dados digitais de pesquisa e ao evidenciarem o risco de obsolescência digital e sinalizarem o desafio de gerir os dados no mundo da pesquisa científica e na Ciência da Informação (CI). Em resposta, apontam a curadoria digital, uma vez que esta trabalha com planejamento e assegura a preservação dos dados em longo prazo. Santos (2014) traça um panorama dos conceitos de curadoria digital com base na revisão de literatura na Ciência da Informação entre os anos de 2000 a 2013. Concluiu que a curadoria digital está em crescimento e faz parte de um termo guarda-chuva com definições similares voltadas para a seleção, o enriquecimento, o tratamento e a preservação da informação no que tange acesso e uso. Evidenciou, ainda, que o termo apresenta variação de significados, é amplo em seus objetos e relaciona-se à gestão da informação digital para preservação, acesso e reuso.

A pesquisa de Siebra, Borba e Miranda (2016) aponta que os desafios em relação à curadoria digital não são somente em termos técnicos, mas também humanos, uma vez que o processo compreende uma sustentabilidade de objetos digitais no longo prazo. A partir da análise sobre o Portfólio Bibliográfico do tema curadoria digital, com a aplicação da ferramenta Proknow-C (ver os resultados do estudo de Machado e Vianna, 2016). Além disso, foi possível identificar alguns conceitos sobre o significado da curadoria digital, ressaltando que há maior número de publicações deste tema na literatura internacional do que na literatura nacional. O Quadro 1 apresenta uma síntese dos principais conceitos encontrados. 
Quadro 1 - Conceitos de Curadoria Digital.

\begin{tabular}{|c|c|c|}
\hline \multicolumn{3}{|c|}{ CONCEITOS DE CURADORIA DIGITAL } \\
\hline Autor/Ano & Conceito & Palavras-Chave \\
\hline $\begin{array}{c}\text { Pennock } \\
(2007)\end{array}$ & $\begin{array}{l}\text { Curadoria Digital é a gestão ativa da informação } \\
\text { digital em todo o seu ciclo de vida, tanto para uso } \\
\text { atual e futuro. }\end{array}$ & $\begin{array}{l}\text { Gestão da informação } \\
\text { Ciclo de vida } \\
\text { Uso atual e futuro }\end{array}$ \\
\hline $\begin{array}{l}\text { Higgins } \\
(2011)\end{array}$ & $\begin{array}{l}\text { O foco da curadoria digital está na gestão por } \\
\text { todo o ciclo de vida do material digital, de forma } \\
\text { que ela permaneça continuamente acessível. } \\
\text { Ampliando a capacidade dos dados serem } \\
\text { recuperados e acessados estão os modelos de } \\
\text { informação, expressos por metadados. Além do } \\
\text { mais, os metadados são ferramentas importantes } \\
\text { para os procedimentos de controle de } \\
\text { autenticação. }\end{array}$ & $\begin{array}{c}\text { Gestão } \\
\text { Ciclo de vida } \\
\text { Acesso } \\
\text { Recuperação } \\
\text { Metadados } \\
\text { Controle }\end{array}$ \\
\hline $\begin{array}{l}\text { Yamaoka, } \\
\text { (2012) }\end{array}$ & $\begin{array}{l}\text { A curadoria digital permite: manter o documento } \\
\text { íntegro e acessível; extrair novos conhecimentos; } \\
\text { preservar a memória da sociedade; e evitar o } \\
\text { retrabalho de recriar os dados já produzidos } \\
\text { anteriormente. Envolve ainda o } \\
\text { compartilhamento e interoperabilidade entre } \\
\text { sistemas, o reuso da informação digital e a } \\
\text { agregação de valor aos documentos digitais. O } \\
\text { foco principal da curadoria digital é garantir o } \\
\text { acesso à informação pelas gerações atuais e } \\
\text { futuras de usuários. }\end{array}$ & $\begin{array}{c}\text { Documento íntegro } \\
\text { Acesso } \\
\text { Preservação } \\
\text { Reuso } \\
\text { Acesso agora e futuro }\end{array}$ \\
\hline
\end{tabular}

Fonte: Machado e Vianna (2016).

A partir desta exposição, é possível perceber que muitos autores convergem em vários aspectos desse conceito. Em virtude disto, pode-se definir Curadoria Digital como sendo um processo de gestão ativa de dados ou informação que agrega valor ao objeto digital em todo o seu ciclo de vida. Tendo a finalidade de uso e reuso da informação no presente e no futuro, utilizando a preservação como um dos seus fortes pilares. Os autores destacam, ainda, outros pontos relevantes do conceito de Curadoria Digital, como o planejamento. Tornando necessário que se conheçam as políticas de gestão da instituição inserida. Outro ponto importante é o cuidado com a manutenção e o controle do processo para evitar que não ocorra obsolescência ao longo do tempo. Ressalta-se ainda, a importância de se trabalhar com o documento na 
íntegra. No caso da digitalização, que é também uma das etapas da curadoria, isso nada mais é do que o arquivamento das informações para uso e reuso.

Higgins (2011) aponta, além dessas questões, o uso de metadados, que podem ampliar "[...] a capacidade dos dados serem recuperados e acessados [...]", trazendo dessa forma novos modelos de informação através de metadados. Kunda e Anderson-Wilk (2011) identificam que é um conjunto de atividades interdisciplinares que fazem a "[...] necessidade para criar de forma mais eficaz, gerir, usar e agregar valor aos ativos digitais por mais tempo.”. Desta forma, observa-se que o conceito de Curadoria Digital fica aberto para que novos conhecimentos sejam inseridos e adaptados às suas práticas. A análise sobre o conceito de Curadoria Digital remete ao papel que esta ocupa e as potencialidades de pesquisa no campo da Ciência da Informação. Tendo em consideração que a informação pode ser descrita como um dado agregado de valor, independente do suporte. O caráter inovador do suporte constitui também um campo interessante de análise, como é o caso dos meios digitais. Os registros de informação aumentaram, incluindo também o meio digital evidenciando a necessidade de novas práticas relacionadas ao gerenciamento, tratamento e à recuperação de todo e qualquer tipo de informação. Na concepção do Data Curation Centre (2015, p. 1, tradução nossa), a Curadoria Digital “[...] mantém e agrega valor à informação digital, tanto no uso presente quanto no futuro e envolve ainda uma gestão ativa e preservação de recursos digitais no ciclo de vida do dado digital, sendo a preservação uma etapa desse processo." Envolve ainda a manutenção, preservação e agregação de valor aos documentos digitais em todo seu ciclo de vida. Sendo assim, é vista como um processo de gestão ativa de dados ou informação que agrega valor ao objeto digital.

\section{Os Objetos Digitais: definição e contextualização}

Com essa expansão da informação, houve o surgimento de um novo espaço digital que engloba os objetos digitais gerados nas instituições e que, a cada dia, vai se multiplicando e ficando mais complexo. Alvarenga (2001) exemplifica estes objetos como: textos de várias naturezas; homepages; lista de discussão; software; padrões; protocolos e dispositivos necessários às tecnologias digitais. 
Hoje os textos, sons e imagens, compartilham do mesmo espaço informacional, sendo a gestão e a organização ferramentas fundamentais para a recuperação desses objetos. Nas palavras de Alvarenga (2001, p. 2) “[...] meio digital se constituiu, portanto, no espaço sem precedentes para o registro e recuperação de documentos textuais, sonoros e imagéticos e que, tem uma enorme gama de possibilidades de armazenagem, memória e formatos [...]”. Na busca de uma conceituação sobre os objetos digitais, Ferreira (2006) elucida que estes são caracterizados como recursos de informação que podem ser representados por meio de uma sequência de dígitos binários, sejam eles nascidos em formato digital, ou mesmo convertidos através de recursos como a digitalização. Alguns aspectos podem ser destacados na conjuntura dos objetos digitais: dependência das tecnologias que abrigam a sua criação, manutenção e armazenamento para que o seu acesso seja possível; atualizações tecnológicas.

Ferreira (2011) aponta que o estudo sobre os objetos digitais pode ser abordado em três dimensões para a preservação digital, a saber: dimensão física, com a perspectiva da inscrição de símbolos em um suporte físico (hardware). A dimensão lógica, na qual os objetos são reconhecidos e processados pelo software. E a dimensão conceptual, em que o objeto é reconhecido e interpretado pelo ser humano (imagens, textos, vídeos, entre outros). A abordagem mais técnica que considera a dimensão física do objeto diz respeito, essencialmente, as funções de leitura e decodificação dos símbolos pelo sistema do computador. Entre alguns dos exemplos de objetos digitais na abordagem física estão: as formas de registro em suportes como disquetes, videocassetes, CDs, DVDs, pendrives, HDs. Ou seja, todos os formatos que precisam de um hardware para que torne possível a conexão e a interpretação pela máquina.

A dimensão lógica, por sua vez, particulariza-se por considerar que o objeto digital é processável por softwares, sendo que suas formas de acesso e leitura (formatos e leitura) são definidas no momento da sua criação. A abordagem lógica abrange os aspectos relativos aos conjuntos estruturados de interpretação de dados por softwares, que possibilitam a leitura de formatos como JPG, JPEG, PDF, Doc. entre outros. Convém lembrar que, apesar de serem formatos diferentes, não carecem da existência de um único suporte, ou 
seja, um documento em formato em Doc. pode ser convertido para outro formato, sem que haja perdas em seu conteúdo (preservação digital). O enfoque conceptual compreende a significação ou, ainda, como as [...] propriedades significativas (THIBODEAU, 2002) dos objetos digitais que perpassam pela validação humana. Ferreira (2009) corrobora ao indicar que nesta fase, o software assume a tarefa de preparar o objeto lógico para receber o significado para o ser humano. Os símbolos ou algoritmos processados na linguagem do computador são representados por sinais analógicos de diferentes formas em um periférico de saída para o ser humano. Em linhas gerais, um documento que decorreu pelos procedimentos anteriores, na então fase conceptual, é gerado o produto do processamento de conteúdos que se difere das etapas anteriores por não apenas decodificar, mas também ao apresentar uma representação compreensível na realidade humana, a exemplo, dos textos, imagens, entre outros tipos de objetos digitais. Vale ressaltar que, apesar de concordar com a proposta de estruturação da definição de objetos digitais, proposta por Thibodeau (2002), a National Library of Australia (NLA) (2003) elege ainda a categoria 'elementos essenciais' aos objetos digitais. Na perspectiva da NLA, esse ponto abrange questões relacionadas à mensagem, o propósito ou as características pelas quais foi decidido preservar o material. Torna-se importante mencionar que existem alguns espaços que trabalham e lidam com esses objetos digitais, como a biblioteca digital. A biblioteca digital é um espaço que engloba esses adventos tecnológicos, possibilitando a comunicação e disseminação da informação digital. Tendo em vista que engloba os vários conhecimentos produzidos pelo mundo, o que a faz ser também um espaço sem paredes, levando informação digital a todos e de várias formas (ALVARENGA, 2001). Conforme Alvarenga (2001, p. 3), a biblioteca digital:

[...] é um conjunto de objetos, concebidos em meio digital, desmaterializados de sua condição física tradicional, constituídos de funções inteiramente novas que lhes garantem a hipertextualidade e caráter multimidiático, tornando-os passíveis de acatar novos e peculiares arranjos e tipos de abordagem, no processo de sua recuperação. 
O cuidado com a preservação de objetos digitais também deve ser levado em consideração, para a garantia de uso no longo prazo, evitando a obsolescência deste tipo de informação. A preservação digital pode partir do armazenamento eletrônico de uma ampla variedade de materiais. Estes, por sua vez, podem resultar em repositórios que precisam ser preservados de acordo com procedimentos, técnicas e tecnologias específicas a cada tipo de material informacional, minimizando assim os riscos de perda desses materiais. Os responsáveis precisam tratar a preservação de forma mais ampla, como no contexto da curadoria. É preciso torná-la estratégia apoiada por uma política de informação sólida e que faça parte do planejamento estratégico da instituição como um todo. Somente desta forma se conseguirá o sucesso, a sustentabilidade e o acesso aos dados no longo prazo, visto que a 'Curadoria Digital' trabalha com processos de preservação da informação armazenada em longo prazo. $\mathrm{Na}$ atual era de informação digital, a ênfase deve ser dada, também, à geração e/ou aquisição de um objeto digital, de acordo com contexto na qual pertence o objeto.

Arellano (2004) aponta que o sucesso desta etapa dependerá das soluções tecnológicas adotadas para tal e dos recursos financeiros que serão envolvidos. $\mathrm{O}$ autor reforça que a preservação digital é uma tarefa desafiadora, porém não impossível, desde que sejam adotadas práticas e estratégias metodológicas bem definidas. Levando-se em consideração a preservação física (foco no conteúdo armazenado em mídia), a preservação lógica (tecnologia para inserção de dados) e a preservação intelectual (foco nos mecanismos para garantir integridade e autenticidade), apontam-se o uso de métodos para esta preservação. De acordo com Arellano (2004), os métodos estruturais requerem investimentos por parte da instituição para a adoção de padrões, elaboração de normas, metadados de preservação digital e montagem de infraestrutura. Já os métodos operacionais implicam em ações aplicadas aos objetos digitais - conservação de software e hardware; migração de suporte; conversão de formatos; emulação e; preservação do conteúdo. $\mathrm{O}$ uso de metadados para a preservação digital permite estratégias operacionais baseadas na conservação de software e hardware, na emulação ou na migração e no gerenciamento de coleções digitais. Além do uso 
de metadados para o processo de tratamento de objetos digitais, tem-se ainda o modelo de referência Open Archival Information System (OAIS) que é um modelo para documentos que precisam de uma preservação digital em longo prazo. Aplicável a qualquer tipo de objeto digital, o modelo está dividido em: objeto, processo, arquivo e modificação de metadados que passam por etapas até a finalização do objeto digital para ser usado e preservado (ARELLANO, 2004). A seguir na Figura 1, apresenta-se o modelo de referência OAIS que pode ser tomado como base ou início no desenvolvimento e planejamento de tratamento de um objeto digital.

Figura 1 - Modelo de referência Open Archival Information System (OAIS).

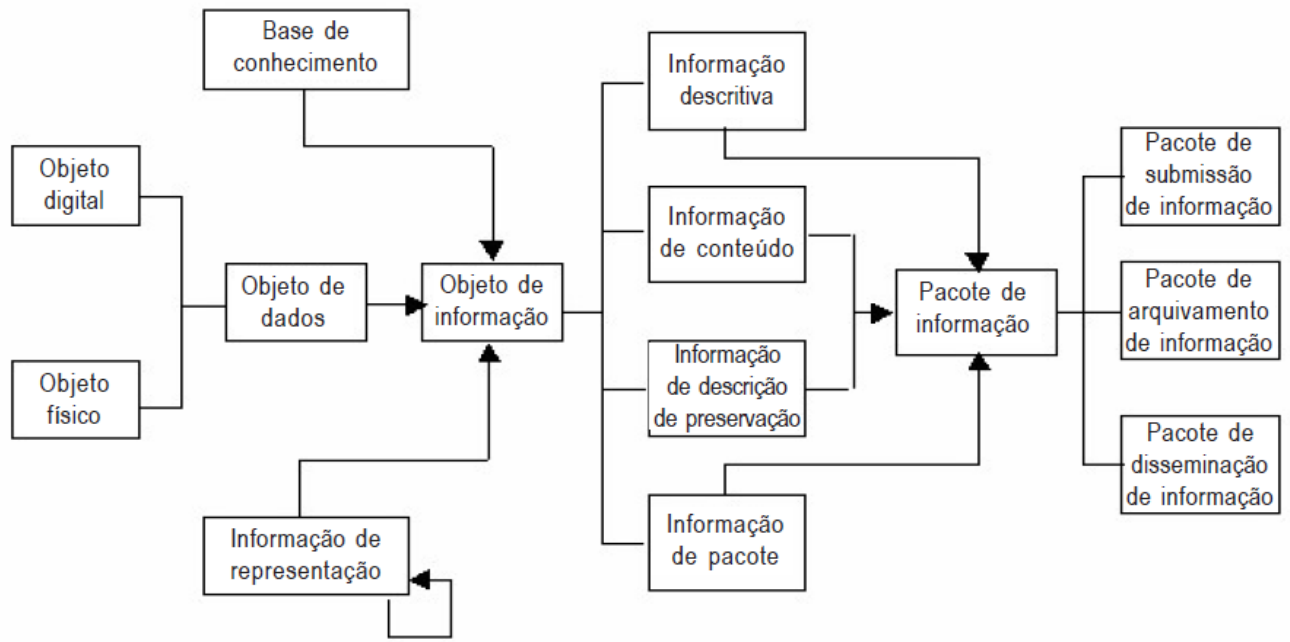

Fonte: Thomaz e Soares (2004).

Este modelo proporciona maior segurança na preservação de objetos digitais, diminuindo os riscos de obsolescência digital. Outra estratégia é a migração e conversão de formatos, na qual se pode preservar o dado digital e garantir o uso por parte dos usuários. A migração e a conversão transferem o objeto para novos formatos quando possível, com o auxílio de hardware e software, convertendo para os padrões estabelecidos (THOMAZ; SOARES, 2004). Outra técnica para a preservação de objetos digitais é a emulação que por meio de programas emuladores imitam o comportamento de um hardware com possível obsolescência, criando um novo software para reproduzir seu 
comportamento. Desta forma, garantindo não só a característica física do objeto, mas o seu conteúdo, visto que apresenta todas as funcionalidades.

\section{Procedimentos metodológicos}

O levantamento do Portfólio Bibliográfico constitui a primeira etapa realizada neste estudo e foi realizada com base na aplicação da ferramenta Proknow-C, conforme mencionado na Seção 2.

A primeira etapa do Proknow-C envolve: definição das palavras-chave; definição do banco de dados; busca dos artigos no banco de dados, selecionado a partir das palavras-chave e; teste de aderência dessas palavras. A seleção do banco de dados de artigos brutos começa com a definição dos eixos de pesquisa ou palavras-chave que devem estar de acordo com a percepção do pesquisador. Para esta pesquisa, usou-se o termo Digital Curation, com o termo definido se segue com o processo que é a definição do banco de dados. Foram escolhidas cinco bases de dados: EBSCO; Emerald; Pro Quest; Scopus; e Science Direct e o horizonte temporal definido entre 2000 e 2015.

Após a pesquisa, os artigos das bases de dados foram exportados para o Software EndNote, programa que permite arquivar dados bibliográficos. A busca pelas palavras-chave, nas cinco bases de dados, resultou em 426 publicações que passaram por uma Filtragem do Banco de Artigos Brutos. Esse processo envolve: eliminação de artigos repetidos; alinhamento pela leitura do título; alinhamento quanto ao reconhecimento científico; alinhamento pela leitura do resumo; disponibilidade do artigo na íntegra; e alinhamento pela leitura integral dos artigos.

Para alcançar os objetivos traçados, além do processo do Proknow- $C$, foi utilizado como instrumento de intervenção, consulta juntos aos especialistas sobre o tema da Curadoria Digital e identificação de objetos digitais, na qual a realização deu-se por meio da aplicação de um formulário on-line.

O formulário foi aplicado com um grupo de especialistas identificados no Proknow-C. Destes 12 especialistas teóricos em nível internacional, foi possível entrar em contato com três deles, tendo sido obtida a resposta de apenas um. Em seguida, realizou-se o contato com os 11 especialistas no âmbito da prática (atuação em nível nacional) e obteve-se o retorno de sete especialistas. 
Portanto, foram consultados um especialista teórico internacional e sete especialistas práticos nacionais que trabalham com Curadoria Digital e com objetos digitais, totalizando uma amostra com oito especialistas para esta etapa da pesquisa. A análise dos resultados permitiu identificar os tipos de objetos digitais existentes atualmente.

\section{Elementos para proposta de framework conceitual para uma Curadoria}

\section{Digital para pessoas com baixa visão}

Tendo em vista que a proposta do estudo resulta na construção de um framework conceitual para curadoria digital das pessoas com baixa visão, torna-se importante expor uma definição de framework conceitual, a fim de que se possa observar a amplitude e as potencialidades da proposta apresentada neste estudo.

O conceito de framework conceitual dessa pesquisa segue a definição apresentada por Tomhave (2005). Para o autor, framework é entendido como um conjunto de conceitos que visa solucionar um determinado problema ou que explora novas ideias, ou seja, esse tipo de framework pode definir conceitos, valores e práticas e, também, incluem orientações para a execução de algo.

A partir dos resultados dos conceitos obtidos no Proknow-C e da consulta sobre a percepção dos especialistas, identificaram-se fatores consideráveis e significativos em relação aos objetos digitais que devem ser ponderados nos seus processos de tratamento e gerenciamento. Torna-se importante enfatizar que este framework tem por pretensão auxiliar profissionais de forma prática nos processos administrativos e de gestão de documentos em formato digital.

Desta forma, propõem-se orientações e direções em relação ao uso de uma curadoria digital, neste caso, especificamente, para os objetos digitais em variados formatos. Os elementos descritos têm por finalidade apoiar os profissionais e ajudar na solução de possíveis problemas. A seguir, a Figura 2 apresenta a proposta do framework conceitual e após, são descritos os elementos e os passos previstos no âmbito da proposta. 
Figura 2 - Framework conceitual para o gerenciamento de informação de uma curadoria digital.
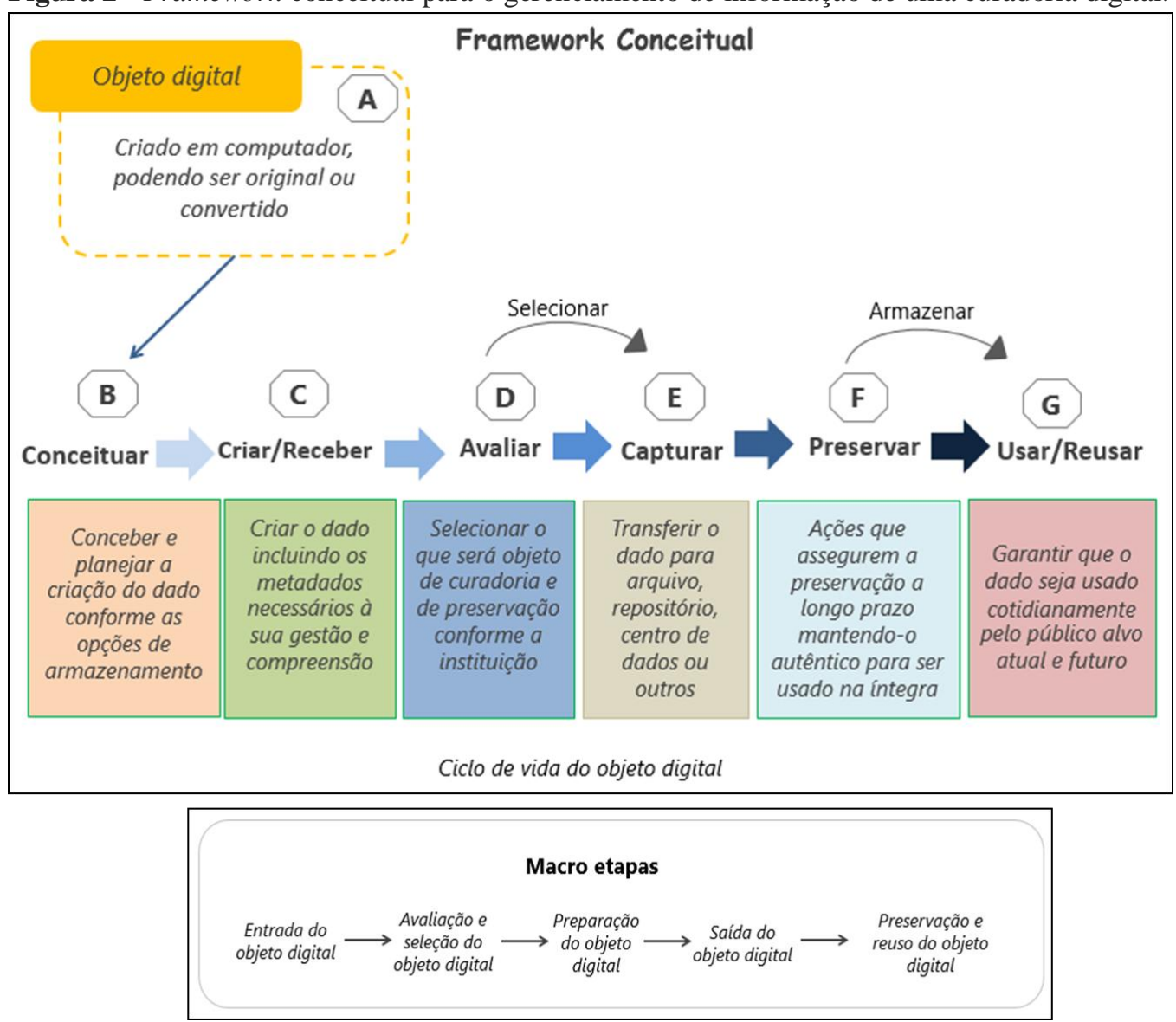

Fonte: Elaborado pelos autores.

Ao ter contato com um documento digital ou objeto digital, recomendase a verificação das seguintes etapas: processo de entrada, preparação e saída, para só então ser usado e reusado. É importante, no momento da etapa de entrada, que haja a identificação desse material por meio da definição do conceito. Na sequência, serão tratados os tópicos do tratamento do objeto que tem o intuito de evitar a sua obsolescência digital e garantir o seu uso futuramente.

É importante enfatizar que as descrições apresentadas a seguir foram baseadas na literatura sobre curadoria digital (conforme a seção de referencial teórico desta pesquisa), sobretudo, o ciclo de vida para o uso de objetos digitais e nas sinalizações das etapas propostas pelo Centro de Curadoria Digital (Data Curation Centre, DCC).

a) na entrada do objeto digital - esta etapa é composta pela conceituação, criação ou pelo recebimento de objetos digitais. Conforme indicações do 
DCC (2017), pode-se conceber e planejar a criação de objetos digitais desde que sigam métodos para capturar os dados e que haja opções para a preservação deles. Em relação à criação, indicam que podem ser produzidos objetos digitais e atribuídos metadados arquivísticos, administrativos, descritivos, estruturais ou técnicos;

b) na avaliação e seleção do objeto digital - fazem parte dessa etapa: a avaliação e a seleção dos objetos digitais. O DCC (DATA CURATION CENTRE, 2017) aponta que passam por estes processos os objetos digitais que precisam de curadoria e preservação para serem utilizados no longo prazo e propõem a orientação documentada, políticas apropriadas, bem como o uso de requisitos de alguma forma legalizados. Pode ocorrer necessidade de reavaliação desses objetos, e, se assim for preciso, é feito o retorno do objeto digital que apresentou falha no processo de avaliação e seleção;

c) na preparação do objeto digital - o momento da captura de um objeto digital constitui-se na integração do objeto por meio de registro, classificação, indexação e/ou arquivamento. Essa ação permite a identificação do objeto na instituição e mostra a qual hierarquia pode pertencer. Dessa forma, estará englobado no sistema da instituição para que se possa seguir com as demais atividades de tratamento e gestão da informação digital;

d) na preservação para o reuso do objeto digital - considerada uma das etapas mais trabalhosas e, também, cautelosas, visto que engloba a preservação e o armazenamento dos objetos digitais. O DCC (DATA CURATION CENTRE, 2017), em relação à preservação de dados digitais, aponta que a conservação digital e a preservação desses dados são processos importantes e que demandam tempo, investimento e ações que promovam a curadoria e a preservação em longo prazo. Aqui, o processo passa por transferência de objetos digitais para arquivos digitais, repositórios digitais confiáveis, centro de dados ou equivalentes que apresentem políticas de documentação adequadas a dados digitais e requisitos legais. A execução de ações nesse sentido deve garantir não só 
a preservação, mas também a retenção, para uso no futuro, dos objetos digitais (DATA CURATION CENTRE, 2017);

e) na saída e uso do objeto digital - o momento da saída de objetos digitais para o uso garante que os usuários reais e potenciais consigam acessar de maneira fácil esses objetos, independente da forma como possam estar disponíveis ou protegidos. Isto assegura que os objetos sejam acessados, usados e reusados desde o primeiro contato em diante (DATA CURATION CENTRE, 2017).

O framework conceitual, apresentado nessa pesquisa, também contempla em suas etapas uma das estratégias da curadoria digital que é o ciclo de vida da curadoria. Sales e Sayão (2012) mostram que as etapas desse ciclo compreendem a descrição e a representação da informação; efetivada pela atribuição de metadados de acordo com os padrões de cada instituição, da definição de um plano de preservação, da manutenção do monitoramento das atividades e da participação no desenvolvimento das ações. Mostram a seguinte sequência para o modelo do ciclo de vida da curadoria digital:

a) conceituar - conceber e planejar a criação do dado, incluindo os métodos de captura e as opções de armazenamento;

b) criar e receber - criar o dado, incluindo o elenco de metadados necessários à sua gestão e compreensão.

c) avaliar e selecionar - avaliar o dado e selecionar o que será objeto para os processos de curadoria e de preservação em longo prazo, de acordo com as políticas de cada instituição.

d) capturar - transferir o dado para um arquivo, repositório, centro de dados ou outro suporte apropriado.

e) ação e preservação - promover ações para assegurar a preservação em longo prazo e a posse do dado de natureza oficial, sendo que as ações devem garantir que o dado permaneça autêntico e capaz de ser usado na íntegra. Tais ações devem incluir limpeza do dado, validação, adição de metadados, preservação e garantia de estruturas de formatos aceitáveis.

f) armazenar - armazenar o dado de forma segura, mantendo assim a ligação com os padrões relevantes.

g) acessar, usar e reusar - assegurar que o dado possa ser cotidianamente acessado tanto pelo público alvo quanto pelos demais usuários interessados no seu reuso.

h) transformar - criar novos dados a partir do original, derivando novos resultados que podem ser publicados. (SALES; SAYÃO, 2012, p. 186, grifo nosso). 
Em virtude disto, percebe-se, então, que nesse processo pode ocorrer também um trabalho de gestão da informação. Os gestores precisam tratar da preservação de forma ampla, como no contexto da curadoria, é preciso torná-la estratégia apoiada por uma política de informação sólida e que faça parte do planejamento estratégico da instituição como um todo. Esta é a condição fundamental para assegurar o sucesso da implementação, a sustentabilidade e o acesso aos dados em longo prazo, tendo em vista que a curadoria digital trabalha com processos de preservação da informação armazenada, podendo proporcionar a expansão do acesso aberto à informação.

\subsection{Demonstração da aplicação do framework}

A partir do framework conceitual apresentado na seção anterior, serão demonstradas possibilidades, por meio de exemplos de objetos digitais para pessoas com baixa visão. Sendo assim, na sequência, são descritos três exemplos de instituições ou lugares que, potencialmente, podem utilizar os objetos digitais. Ressalta-se que esta seção apresentará testes intencionais com o propósito de simular a aplicabilidade do framework conceitual para o gerenciamento da informação em objetos digitais. Os especialistas consultados nesta pesquisa mencionaram os repositórios institucionais como locais de identificação destes objetos digitais. Um repositório institucional pode adquirir ou criar um objeto/documento digital, de forma digitalizada ou originada digitalmente. O gestor, pessoa ou equipe responsável pelos objetos digitais, ao se depararem, por exemplo, com a entrada de trabalhos acadêmicos no formato PDF na instituição poderão:

a) identificar o objeto no momento que entrar na instituição por meio do seu conceito, ou seja, identificar que tipo de objeto digital tem em mãos;

b) depois de identificado o material, seja este criado ou recebido, poderá ser armazenado de acordo com as políticas do repositório, levando-se em conta os metadados;

c) logo após, passa-se para o processo de avaliação desse objeto digital.

Nesse momento, deverá ser identificado se o objeto será usado ou não, 
podendo aqui ser aplicado o processo de curadoria digital, de acordo com as políticas do repositório;

d) selecionar o tipo do objeto digital para o processo de captura através de transferência para o repositório, esta podendo ser feita por meio de digitalização ou cópia;

e) depois de preparado o objeto passa para a etapa de digitalização, esta irá assegurar não só a preservação dos documentos digitais no repositório, como também, o uso no presente do material e reuso para os futuros usuários. A preservação deve seguir as políticas de cada tipo de repositório, podendo ser feita por meio da cópia, uso de metadados, emulação ou migração, gerenciamento das coleções digitais, ou uso do modelo de referência de protocolo Open Archival Information System (OAIS);

f) depois de passado pelas políticas de preservação, será feita a catalogação e/ou classificação desse objeto digital, podendo ser por meio de indexação específica das políticas do repositório, do AACR2, RDA, CDD ou CDU;

g) finalizada as etapas de preparação do objeto digital para ser, então, disponibilizado, este poderá ser armazenado corretamente e poderá ser usado nos mecanismos de saídas do repositório, nos quais estará disponível aos usuários reais e potenciais no agora e no futuro.

É importante nesse processo que o repositório institucional crie mecanismos de propagação desses objetos digitais disponíveis, facilitando, assim, o acesso à informação digital para o seu público. Pode ser por meio da criação de um espaço específico de novas aquisições, ou link específico de TCCs, dissertações e teses, na página online do repositório. Desse modo, os internautas poderão ter conhecimento e acesso do que se tem disponível. 
Figura 3 - Simulação de entrada de trabalhos em PDF em instituição.

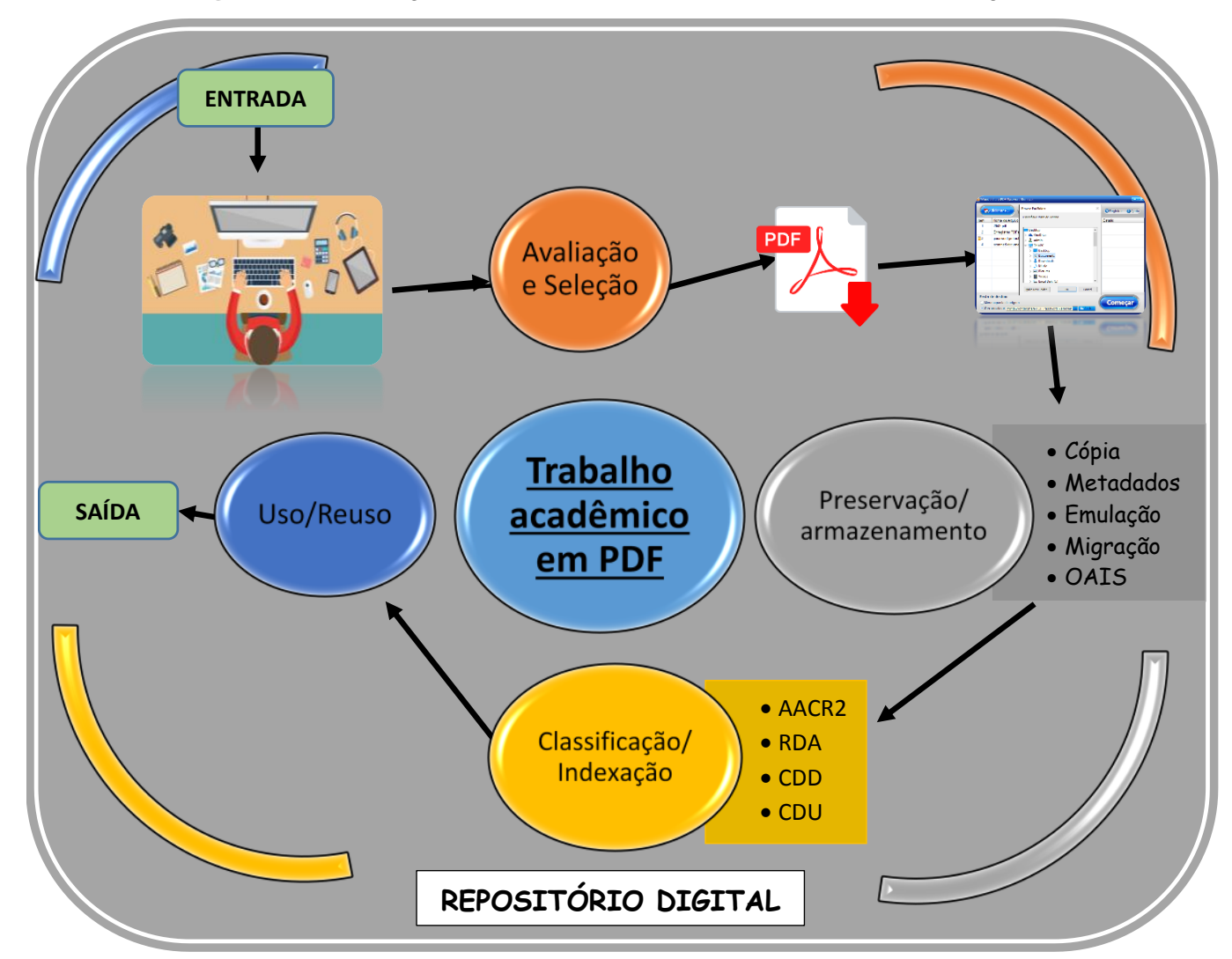

Fonte: Elaborado pelos autores.

\section{Considerações finais}

Dentre as motivações para este, menciona-se a identificação de lacunas de estudos empíricos que tratem de um modelo auxiliador no processo de tratamento e gestão de objetos digitais. Assim, identificou-se a ausência de um instrumento geral para o tratamento dos objetos digitais, e também específicos para pessoas com baixa visão, confirmação obtida no processo de revisão de literatura.

É importante que a literatura evidencie algumas iniciativas em relação à curadoria digital e aos objetos digitais, porém ainda tímidas no que se refere à informação digital disponível para pessoas com baixa visão, sendo que não foi encontrado um número mínimo de estudos que abordassem esta temática. Como o objetivo era investigar a respeito dessa população, prosseguiu-se no desenvolvimento, o que não significa que o resultado não seja também aplicável a pessoas sem deficiência. Os resultados da pesquisa convergiram da literatura científica e da aplicação de questionário junto aos especialistas. Tanto 
na teoria como na prática, ainda não existem iniciativas suficientes que englobem o desenvolvimento de uma curadoria digital para pessoas com baixa visão. Na teoria, observa-se que os assuntos estão mais voltados para perspectivas conceituais, documentais, e apenas iniciais do processo cíclico para uma Curadoria Digital. Na prática, identificou-se que já acontecem avanços significativos em relação aos objetos digitais disponíveis. No entanto, percebeuse a necessidade de mais auxílios aos profissionais da informação que têm atuado nessa vertente, para que possam desenvolver com melhor praticidade e segurança o processo de gestão da informação nas respectivas instituições.

Além de propor um framework conceitual, procurou-se demonstrar a sua aplicabilidade em ambientes que, usualmente, utilizam objetos digitais no dia a dia, criando situações prováveis de aplicação do framework, demonstrando o percurso de entrada, processamento, preservação e saída da informação digital em instituições como: repositórios, arquivos e bibliotecas digitais.

As sinalizações apresentadas aqui versam sobre uma forma de praticar as etapas do processo de uma curadoria digital para os objetos digitais em vários tipos de instituições e objetos digitais, ressaltando que as iniciativas podem seguir os modelos, padrões e protocolos de cada instituição, com intuito de estabelecer melhores práticas no ambiente profissional no que tange o tratamento e o gerenciamento da informação digital.

Recomenda-se a utilização dos procedimentos do framework conceitual por parte dos profissionais, tendo em vista o desenvolvimento de uma curadoria digital para o gerenciamento da informação em objetos digitais.

Essa prática potencializará as futuras melhorias e adaptações das especificidades nos diversos contextos que se fazem presentes os documentos digitais para pessoas com deficiência visual.

Espera-se que este estudo contribua para os futuros estudos empíricos na área de Ciência da Informação. Nestes termos, ressalta-se como possibilidade de estudos futuros:

a) investigação sobre a aderência da proposta a Curadoria Digital para pessoas sem deficiência, ou seja, generalidades e especificidades de um modelo geral e/ou específico; 


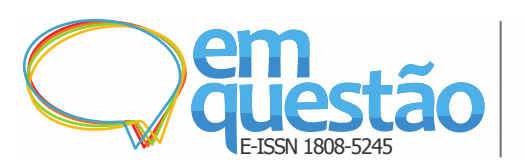

Framework conceitual para o desenvolvimento de Curadoria Digital para pessoas com baixa visão Kettuly Costa Machado, Willian Barbosa Vianna e Ana Clara Cândido

b) interfaces necessárias para criação e implantação de um sistema integrado de gestão da informação digital que poderá ser adaptado aos tipos de organizações e objetos existentes;

c) criação de critérios de usabilidade para os objetos digitais disponíveis e criação de modelos de requisitos para o manuseio dos tipos de objetos digitais para pessoas com deficiência visual.

\section{Referências}

ALVARENGA, Lídia. A teoria do conceito revisitada em conexão com ontologias e metadados no contexto das bibliotecas tradicionais e digitais. Data Grama Zero, Rio de Janeiro, v. 2, n. 6, p. 1-13, dez. 2001.

AMARAL, Roberto. Ciência e tecnologia: desenvolvimento e inclusão social. Brasília: UNESCO, Ministério da Ciência e Tecnologia, 2003.

ARELLANO, Miguel Angel. Preservação de documentos digitais. Ciência da Informação, Brasília, v. 33, n. 2, p. 15-27, maio/ago. 2004.

BATIMARCHI, Susana. EMC divulga estudo sobre universo digital. Instituto Information Management [portal], São Paulo, 2012.

BRASIL. Ministério da Educação. Saberes e práticas da inclusão: desenvolvendo competências para o atendimento às necessidades educacionais especiais de alunos cegos e de alunos com baixa visão. 2. ed. Brasília: MEC, 2006.

DATA CURATION CENTRE. What is digital curation? [2017].

FERREIRA, Carla Alexandra Silva. Preservação da informação digital: uma perspectiva orientada para as bibliotecas. 2011. 115f. Dissertação (Mestrado em Informação, Comunicação e Novos Media) - Faculdade de Letras, Universidade de Coimbra, Coimbra, 2011.

FERREIRA, Miguel. Introdução à preservação digital: conceitos, estratégias e actuais consensos. Guimarães: Escola de Engenharia da Universidade do Minho, 2006.

FERREIRA, Miguel. Preservação de longa duração de informação digital no contexto de um arquivo histórico. 2009. 96 f. Tese (Doutorado em

Tecnologias e Sistemas de Informação) - Escola de Engenharia, Universidade do Minho, Guimarães, 2009.

HIGGINS, Sarah. Digital curation: the emergence of a new discipline. The International Journal of Digital Curation, Bath- Somerset, v. 6, n. 2, 2011. 


\section{INSTITUTO BRASILEIRO DE GEOGRAFIA E ESTATÍSTICA. Censo Demográfico 2010. Rio de Janeiro: IBGE, 2011.}

KUNDA, Sue; ANDERSON-WILK, Mark. Community stories and institutional stewardship: digital curation's dual roles of story creation and resource preservation. Libraries and the Academy, Baltimore, v. 11, n. 4, p. 895-914, 2011.

MACHADO, Kettuly Costa; VIANNA, William. Curadoria Digital e Ciência da Informação: correlações conceituais relevantes para apropriação da informação. In: ENCONTRO NACIONAL DE PESQUISA EM PÓS-GRADUAÇÃO EM CIÊNCIA DA INFORMAÇÃO, 17., 2016, Salvador. Anais... Salvador: UFBA, 2016. p. 1-18.

NATIONAL LIBRARY OF AUSTRALIA. Guidelines for the preservation of digital heritage Organization. Paris: Unesco, 2003.

PENNOCK, Maureen. Digital curation: A lifecycle approach to managing and preserving usable digital information. Library and Archives, [S.1.], n. 1, v. 18, p. 1-3, jan. 2007. Disponível em:

<http://www.ukoln.ac.uk/ukoln/staff/m.pennock/publications/docs/libarch_curation.pdf>. Acesso em: 18 abr. 2015.

SANTOS, Thayse Natália Cantanhede. Curadoria digital: o conceito no período de 2000 a 2013. 2014. 166 f. Dissertação (Mestrado em Ciência da Informação) - Faculdade de Ciência da Informação, Universidade de Brasília, Brasília, 2014.

SAYÃO, Luis Fernando; SALES, Luana Farias. Curadoria digital: um novo patamar para preservação de dados digitais de pesquisa. Informação e Sociedade, João Pessoa, v. 22, n. 3, p. 179-191, set./out.2012.

SIEBRA, Sandra de Albuquerque; BORBA, Vildeane da Rocha; MIRANDA, Májory Karoline Fernandes de Oliveira. Curadoria digital: um termo interdisciplinar. In: ENCONTRO NACIONAL DE PESQUISA EM CIÊNCIA DA INFORMAÇÃO, 17., Salvador. Anais... Salvador: UFBA, 2016.

SOLIMAN, Fawzy. Application of knowledge management for hazard analysis in the Australian dairy industry. Journal of Knowledge Management, Bingley v. 4, n. 4, p. 287-294, 2000.

THIBODEAU, Kenneth. Overview of technological approaches to digital preservation and challenges in coming years. In: THE STATE OF DIGITAL PRESERVATION: AN INTERNATIONAL PERSPECTIVE: CONFERENCE 2002. Proceedings...

Washington: CLIR and Library of Congress, 2002. Disponível em: <http://www.clir.org/pubs/reports/pub107/contents.html/thibodeau.html>. Acesso em: 22 abr. 2015. 
THOMAZ, Katia P.; SOARES, Antonio José. A preservação digital e o modelo de referência Open Archival Information System (OAIS). DataGramaZero, Rio de Janeiro, v. 5 n. 1, p. 1-17, 2004.

TOMHAVE, B. L. Alphabet soup: making sense of models, frameworks, and methologies. 2005. Disponível em:

$<$ http://www.secureconsulting.net/Papers/Alphabet_Soup.pdf $>$. Acesso em: 12 jul. 2017.

YAKEL, Elizabeth. Archives and manuscripts: digital curation.

International Digital Library Perspectives, Bingley, v. 23, n. 4, p. 335340, 2007. Disponível em: <https://www.emeraldinsight.com/doi/pdfplus/10.1108/10650750710831 466>. Acesso em: 20 abr. 2015.

YAMAOKA, Eloi Juniti. Ontologia para mapeamento da dependência tecnológica de objetos digitais no contexto da curadoria e preservação digital. AtoZ, Curitiba, v. 1, n. 2, p. 65-78, jan./dez. 2012. Disponível em: $<$ https://revistas.ufpr.br/atoz/article/view/41313/25239>. Acesso em: 18 abr. 2015.

\title{
Conceptual framework for the development of Digital Curation for people with low vision
}

\begin{abstract}
This study aims to propose a conceptual framework for the development of Digital Curation for people with low vision. The methodological procedures comprehend two main steps: the application of the Proknow-C tool for the analysis of the bibliographic portfolio and a consultation with specialists, in the theoretical and practical scope, about Digital Curation. We identified the digital objects that are part of informational context, bringing it to the reality of people with low vision. From the theoretical basis, the conceptual framework proposal was constructed and an exercise of application was carried out to illustrate the operation. Finally, the conceptual framework developed can help the professionals that work with the digital information in the processes of treatment of a digital object, helping the professionals that deal with the information management.
\end{abstract}

Keywords: Information management. Conceptual framework. Digital curation. Digital object. People with low vision. 